\title{
New susceptibility loci in MYL2, C12orf51 and OAS1 associated with 1-h plasma glucose as predisposing risk factors for type 2 diabetes in the Korean population
}

\author{
Min Jin Go ${ }^{1}$, Joo-Yeon Hwang ${ }^{1}$, Young Jin $\mathrm{Kim}^{1}$, Ji Hee $\mathrm{Oh}^{1}$, Yeon-Jung $\mathrm{Kim}^{1}$, Soo Heon Kwak ${ }^{2}$, \\ Kyung Soo Park ${ }^{2,3}$, Juyoung Lee ${ }^{1}$, Bong-Jo Kim ${ }^{1}$, Bok-Ghee Han ${ }^{1}$, Myeong-Chan Cho ${ }^{4}$, Yoon Shin Cho ${ }^{1,5}$ \\ and Jong-Young Lee ${ }^{1}$
}

Most recently, 1-h hyperglycemia has been recognized as an additional risk factor for type 2 diabetes. To date, previous genome-wide association studies for glycemic traits have a limited impact on the fasting state and 2-h plasma glucose level in an oral glucose challenge. To identify genetic susceptibility in different stages of glucose tolerance, we performed a metaanalysis for glycemic traits including 1-h plasma glucose (1-hPG) from 14232 non-diabetic individuals in the Korean population. Newly implicated variants (MYL2, C12orf51 and OAS1) were found to be significantly associated with 1-hPG. We also demonstrated associations with gestational diabetes mellitus. Our results could provide additional insight into the genetic variation in the clinical range of glycemia.

Journal of Human Genetics (2013) 58, 362-365; doi:10.1038/jhg.2013.14; published online 11 April 2013

Keywords: GDM; glycemic trait; GWAS; 1-h plasma glucose; T2D

\section{INTRODUCTION}

Impaired glucose tolerance and impaired fasting glucose as intermediate risk factors for type 2 diabetes (T2D) are characterized by reduced early-phase insulin secretion. ${ }^{1}$

Recently, 1-h plasma glucose (1-hPG) was associated with deterioration of glucose tolerance and alterations by insulin sensitivity. ${ }^{2}$ After adjustment for 1-hPG, the high fasting plasma glucose (FPG) level was not associated with an increase in the incidence of T2D. These prior results were particularly apparent for increased 1-hPG than other plasma glucose stages in an oral glucose challenge. ${ }^{3}$

Despite identification of novel loci from large-scale association analyses in Eurocentric consortium, most previous studies have a limited impact on FPG and 2-hPG values for glycemic traits. ${ }^{4-6}$ Although FPG and 2-hPG are useful as gold standards for T2D risk, identifying new genetic susceptibility predisposing to early plasma glucose condition would be more valuable as an important parameter for risk stratification in glucose abnormalities.

\section{MATERIALS AND METHODS}

Study subjects

The Korea Association REsource study subjects were recruited based on the Korean Genome Epidemiologic Study project. A total of 10038 participants, 40-69 years old, were registered at the first stage of survey performed in 20012002. Details of this study population have been recently described. ${ }^{7}$ For this study, we excluded known diabetics individuals treated with anti-diabetic medicine and individuals with FPG more than $7 \mathrm{mmoll}^{-1}$. Consequently, 7696 non-diabetic subjects were only tested for T2D-related quantitative traits such as FPG, 1-h glucose and 2-h glucose after oral glucose administration. Seventy-five grams of glucose was used for oral glucose administration in the Korea Association Resource and Health 2 cohort, respectively. Subjects for the replication study were selected from the community-based Health 2 cohort as described previously. ${ }^{7}$ We examined 6536 non-diabetic subjects selected from the 8500 participants (aged 40-69 years). The gestational diabetes mellitus $(\mathrm{GDM})$ group $(n=468)$ was selected from a hospital-based cohort, which recruited GDM women between January 1996 and February 2003 from Cheil General Hospital. For screening, $50 \mathrm{~g}$ 1-h oral glucose tolerance test was

${ }^{1}$ Division of Structural and Functional Genomics, Center for Genome Science, Korea National Institute of Health, Osong Health Technology Administration Complex, Chungcheongbuk-do, Republic of Korea; ${ }^{2}$ Department of Internal Medicine, Seoul National University College of Medicine, Seoul, Republic of Korea; ${ }^{3}$ WCU Department of Molecular Medicine and Biopharmaceutical Sciences, Graduate School of Convergence Science and Technology and College of Medicine, Seoul National University, Seoul, Republic of Korea; ${ }^{4}$ National Institute of Health, Osong Health Technology Administration Complex, Chungcheongbuk-do, Republic of Korea and ${ }^{5}$ Department of Biomedical Science, Hallym University, Chuncheon, Republic of Korea

Correspondence: Dr YS Cho, Department of Biomedical Science, Hallym University, Chuncheon 200-702, Republic of Korea.

E-mail: yooncho33@hallym.ac.kr

or Dr J-Y Lee, Division of Structural and Functional Genomics, Center for Genome Science, Korea National Institute of Health, Osong Health Technology Administration Complex Chungcheongbuk-do, 363-951, Republic of Korea.

E-mail: leejy63@gmail.com

Received 1 November 2012; revised 14 January 2013; accepted 21 January 2013; published online 11 April 2013 
performed during 24-28 weeks of gestation. A glucose level of $130 \mathrm{mg} \mathrm{dl}^{-1}$ or higher was considered positive and warranted diagnostic 100 goral glucose tolerance test. The glucose and insulin concentrations were measured at 0, 1, 2 and $3 \mathrm{~h}$ of glucose challenge. The threshold glucose values for diagnosis of GDM were fasting $\geqslant 105 \mathrm{mg} \mathrm{dl}^{-1}, 1 \mathrm{~h} \geqslant 190 \mathrm{mg} \mathrm{dl}^{-1}, 2 \mathrm{~h} \geqslant 165 \mathrm{mg} \mathrm{dl}^{-1}$ and $3 \mathrm{~h} 145 \geqslant \mathrm{mg} \mathrm{dl}^{-1}$. Mean gestational age at diagnosis of GDM was $27.9 \pm 2.9$ weeks. Non-diabetic control subjects $(n=1242)$ were selected from two population-based cohort studies, the rural Ansung and the urban Ansan cohorts. The two cohorts comprised the Korean Genome Epidemiology Study. Only women were eligible as control group according to the following criteria: age $\geqslant 50$ years, no previous history of T2D, no first-degree relatives with T2D, FPG level $<100 \mathrm{mg} \mathrm{dl}^{-1}$ and $\mathrm{HbAlc}<6.0 \%$.

\section{Genotyping and quality control}

A total of 10004 samples were genotyped using Affymetrix Genome-Wide Human SNP 5.0 arrays (Affymetrix, Santa Clara, CA, USA) and processed with Bayesian Robust Linear Modeling using the Mahalanobis Distance (BRLMM) genotyping algorithm. ${ }^{8}$ Markers with a high missing call rate $(>5 \%)$, minor allele frequency $<1 \%$ and significant deviation from Hardy-Weinberg equilibrium $\left(P<1 \times 10^{-6}\right)$ were excluded. The remaining 357789 SNPs were used in subsequent analyses for association. For the replication study in Health 2 $(n=6536)$, we genotyped 18 SNPs in 21 SNPs that showed the strongest signal in stage 1 . We performed genotype assay using the $\mathrm{TaqMan}^{\mathrm{TM}}$ reaction for 1 SNP (rs2074356), and using GoldenGate assay (Illumina Inc., San Diego, CA, USA) for 17 SNPs. ${ }^{9}$ For three SNPs (rs16856247, rs16925807 and $\left.r s 12437833\right)$, we were not able to design probes on the de novo genotyping assay.

\section{Genotype imputation}

Imputation analysis was performed using IMPUTE against all of the HapMap Asian (JPT/CHB) population (release 22/NCBI, build 36, and dbSNP build 129) for a total of 1573409 SNPs. We dropped SNPs with a posterior probability score $(<0.90)$, high genotype information content (info $<0.5$ ),

Table 1 Descriptive statistics for glycemic traits examined in GWAS and replication study populations

\begin{tabular}{lcc}
\hline Trait & KARE $(\mathrm{n}=7696)$ & Health $2(\mathrm{n}=6536)$ \\
\hline Age & $51.64 \pm 8.80$ & $56.14 \pm 7.94$ \\
Sex (M/F) & $3584 / 4112$ & $2584 / 3952$ \\
BMI & $24.48 \pm 3.08$ & $24.35 \pm 3.14$ \\
FPG $\left(\mathrm{mmol} \mathrm{I}^{-1}\right)$ & $4.62 \pm 0.49$ & $5.03 \pm 0.50$ \\
1-hPG $\left(\mathrm{mmol} \mathrm{I}^{-1}\right)$ & $7.94 \pm 2.26$ & $8.78 \pm 2.48$ \\
2-hPG $\left(\mathrm{mmol} \mathrm{I}^{-1}\right)$ & $6.42 \pm 1.68$ & $6.66 \pm 1.79$
\end{tabular}

Abbreviations: BMI, body mass index; FPG, fasting plasma glucose; GWAS, genome-wide association studies; KARE, Korea Association Resource; 1-hPG, 1-h plasma glucose after an oral glucose tolerance test; 2 -hPG, 2-h plasma glucose after an oral glucose tolerance test.
Hardy-Weinberg equilibrium $\left(P<1 \times 10^{-7}\right)$, SNP missing rate $(>0.1)$ and minor allele frequency $(<0.01)$.

\section{Association analyses}

Associations were analyzed using the PLINK (http://pngu.mgh.harvard.edu/ $\sim$ purcell/plink/) and SAS program (version 9.1; SAS Institute Inc., Cary, NC, USA). The diabetes-related quantitative traits were tested by multivariate linear regression analysis in an additive genetic model ( 1 -d.f.) including age, sex and recruitment area as covariates. All traits were normally distributed and no transformations were required. The quantile-quantile (Q-Q) plots of genomewide $P$ values showed deviations from the null distribution due to the strong associations observed for each quantitative trait. The genomic inflation factor ( $\lambda$ ) was estimated from the median of the $\chi^{2}$ statistic divided by $0.456 .{ }^{10}$ Metaanalysis was performed from the combined result using effect size and standard errors estimated of each study. The results of all cohorts were combined by an inverse-variance meta-analysis method assuming fixed effects. Cochran's $Q$ test was used to assess heterogeneity between three studies. All meta-analysis calculations were performed using R program (version 2.7.1). ${ }^{11}$

\section{RESULTS}

All 357789 SNPs were tested using linear regression analysis adjusted for age, sex and recruitment area. Each trait of genomic control inflation factor $(\lambda)$ was estimated below 1.1 for assessment of population structure. The $\lambda$-value of the initial genome-wide association study consistently showed no systematic inflation $(\lambda=1.012$ 1.029). The Q-Q plots for the trend test of all traits showed that the distribution of observed $P$-values deviated from expected $P$-values only in the extreme tail, suggesting true-positive association signals (Supplementary Figures 1 and 2).

For glycemic traits (FPG, 1-hPG and 2-hPG), we examined a twostage design involving a discovery set of 7696 individuals sampled from population-based samples (Korea Association ReEsource) and a replication set of 6536 individuals from an independent populationbased sample (Health 2). The basic characteristics of the participants are described in Table 1. Finally, a meta-analysis combining stage 1 and 2 data identified a total of 11 SNPs reaching a genome-wide significant level (Table 2).

In our results, GCK at $7 \mathrm{p} 15$ was more significantly replicated in FPG (rs1799884, $\left.P=4.53 \times 10^{-18}\right)$ but far less significant in 1 -h and 2-hPG $\left(P=2.82 \times 10^{-9}\right.$ and $\left.P=2.59 \times 10^{-10}\right)$, respectively. In addition, CDKAL1 at $6 \mathrm{p} 22$ was most significantly replicated with $1-\mathrm{hPG}$ (rs9348440, $P=3.13 \times 10^{-19}$ ). MTNR1B at $11 \mathrm{q} 21$ also showed strong associations with FPG and 1-hPG (rs10830962, $P=4.84 \times 10^{-13}$ and $\left.P=3.24 \times 10^{-12}\right)$, respectively.

Table 2 Association results for glycemic traits from a combined meta-analysis that exceed a genome-wide threshold

\begin{tabular}{|c|c|c|c|c|c|c|c|c|c|c|c|c|c|c|}
\hline \multirow{2}{*}{ Trait } & \multirow{2}{*}{ CHR } & \multirow{2}{*}{ SNP } & \multirow{2}{*}{ Gene } & \multirow{2}{*}{$A 1$} & \multicolumn{3}{|c|}{ KARE } & \multicolumn{3}{|c|}{ Health 2} & \multicolumn{4}{|c|}{ Meta analysis } \\
\hline & & & & & $\mathrm{N}$ & Beta \pm s.e.m. & $P$ & $\mathrm{~N}$ & Beta \pm s.e.m. & $P$ & $\mathrm{~N}$ & Beta \pm s.e.m. & $\mathrm{P}$ & Hetero P \\
\hline FPG & $\begin{array}{c}7 \\
11 \\
12\end{array}$ & $\begin{array}{c}\text { rs1799884 } \\
\text { rs10830962 } \\
\text { rs2074356 }\end{array}$ & $\begin{array}{l}\text { GCK } \\
\text { MTNR1B } \\
\text { C12orf51 }\end{array}$ & $\begin{array}{l}\mathrm{A} \\
\mathrm{C} \\
\mathrm{T}\end{array}$ & $\begin{array}{l}7685 \\
7552 \\
7695\end{array}$ & $\begin{array}{r}0.065 \pm 0.010 \\
0.036 \pm 0.008 \\
-0.054 \pm 0.011\end{array}$ & $\begin{array}{l}4.06 \mathrm{E}-11 \\
3.49 \mathrm{E}-06 \\
5.42 \mathrm{E}-07\end{array}$ & $\begin{array}{l}6526 \\
6529 \\
6498\end{array}$ & $\begin{array}{r}0.061 \pm 0.011 \\
0.049 \pm 0.009 \\
-0.070 \pm 0.012\end{array}$ & $\begin{array}{l}2.14 \mathrm{E}-08 \\
1.60 \mathrm{E}-08 \\
1.43 \mathrm{E}-08\end{array}$ & $\begin{array}{l}14211 \\
14081 \\
14193\end{array}$ & $\begin{array}{r}0.063 \pm 0.007 \\
0.041 \pm 0.006 \\
-0.061 \pm 0.008\end{array}$ & $\begin{array}{l}4.53 \mathrm{E}-18 \\
4.84 \mathrm{E}-13 \\
6.03 \mathrm{E}-14\end{array}$ & $\begin{array}{l}0.8161 \\
0.2647 \\
0.3249\end{array}$ \\
\hline 1-hPG & $\begin{array}{c}6 \\
7 \\
11 \\
12 \\
12 \\
12\end{array}$ & $\begin{array}{c}\text { rs9348440 } \\
\text { rs1799884 } \\
\text { rs10830962 } \\
\text { rs12229654 } \\
\text { rs2074356 } \\
\text { rs11066453 }\end{array}$ & $\begin{array}{l}\text { CDKAL1 } \\
\text { GCK } \\
\text { MTNR1B } \\
\text { MYL2 } \\
\text { C12orf51 } \\
\text { OAS1 }\end{array}$ & $\begin{array}{l}A \\
A \\
C \\
G \\
T \\
G\end{array}$ & $\begin{array}{l}7651 \\
7641 \\
7508 \\
7650 \\
7651 \\
7595\end{array}$ & $\begin{array}{r}0.214 \pm 0.036 \\
0.232 \pm 0.046 \\
0.179 \pm 0.036 \\
-0.262 \pm 0.051 \\
-0.296 \pm 0.050 \\
-0.290 \pm 0.054\end{array}$ & $\begin{array}{l}3.72 \mathrm{E}-09 \\
4.47 \mathrm{E}-07 \\
6.16 \mathrm{E}-07 \\
2.60 \mathrm{E}-07 \\
3.65 \mathrm{E}-09 \\
8.52 \mathrm{E}-08\end{array}$ & $\begin{array}{l}6522 \\
6520 \\
6523 \\
6525 \\
6492 \\
6523\end{array}$ & $\begin{array}{r}0.290 \pm 0.042 \\
0.175 \pm 0.054 \\
0.207 \pm 0.042 \\
-0.299 \pm 0.060 \\
-0.357 \pm 0.061 \\
-0.175 \pm 0.064\end{array}$ & $\begin{array}{c}5.99 \mathrm{E}-12 \\
0.0013 \\
1.01 \mathrm{E}-06 \\
6.70 \mathrm{E}-07 \\
4.10 \mathrm{E}-09 \\
0.0062\end{array}$ & $\begin{array}{l}14173 \\
14161 \\
14031 \\
14175 \\
14143 \\
14121\end{array}$ & $\begin{array}{r}0.246 \pm 0.028 \\
0.208 \pm 0.035 \\
0.191 \pm 0.027 \\
-0.277 \pm 0.039 \\
-0.321 \pm 0.039 \\
-0.242 \pm 0.041\end{array}$ & $\begin{array}{l}3.13 \mathrm{E}-19 \\
2.82 \mathrm{E}-09 \\
3.24 \mathrm{E}-12 \\
8.83 \mathrm{E}-13 \\
1.04 \mathrm{E}-16 \\
4.54 \mathrm{E}-09\end{array}$ & $\begin{array}{l}0.1707 \\
0.4213 \\
0.6192 \\
0.6407 \\
0.4335 \\
0.1717\end{array}$ \\
\hline 2-hPG & $\begin{array}{l}7 \\
12\end{array}$ & $\begin{array}{l}\text { rs1799884 } \\
\text { rs2074356 }\end{array}$ & $\begin{array}{l}\text { GCK } \\
\text { C12orf51 }\end{array}$ & $\begin{array}{l}A \\
T\end{array}$ & $\begin{array}{l}7647 \\
7657\end{array}$ & $\begin{array}{r}0.186 \pm 0.034 \\
-0.182 \pm 0.037\end{array}$ & $\begin{array}{l}3.97 \mathrm{E}-08 \\
8.52 \mathrm{E}-07\end{array}$ & $\begin{array}{l}6519 \\
6491\end{array}$ & $\begin{array}{r}0.129 \pm 0.039 \\
-0.140 \pm 0.044\end{array}$ & $\begin{array}{l}0.0009 \\
0.0015\end{array}$ & $\begin{array}{l}14166 \\
14148\end{array}$ & $\begin{array}{r}0.162 \pm 0.026 \\
-0.165 \pm 0.028\end{array}$ & $\begin{array}{l}2.59 \mathrm{E}-10 \\
5.91 \mathrm{E}-09\end{array}$ & $\begin{array}{l}0.2753 \\
0.4661\end{array}$ \\
\hline
\end{tabular}

Abbreviations: BMI, body mass index; CHR, chromosome; FPG, fasting plasma glucose; KARE, Korea Association ReEsource; 1-hPG, 1-h plasma glucose after an oral glucose tolerance test; 2-hPG, 2-h plasma glucose after an oral glucose tolerance test; SNP, single-nucleotide polymorphism. 


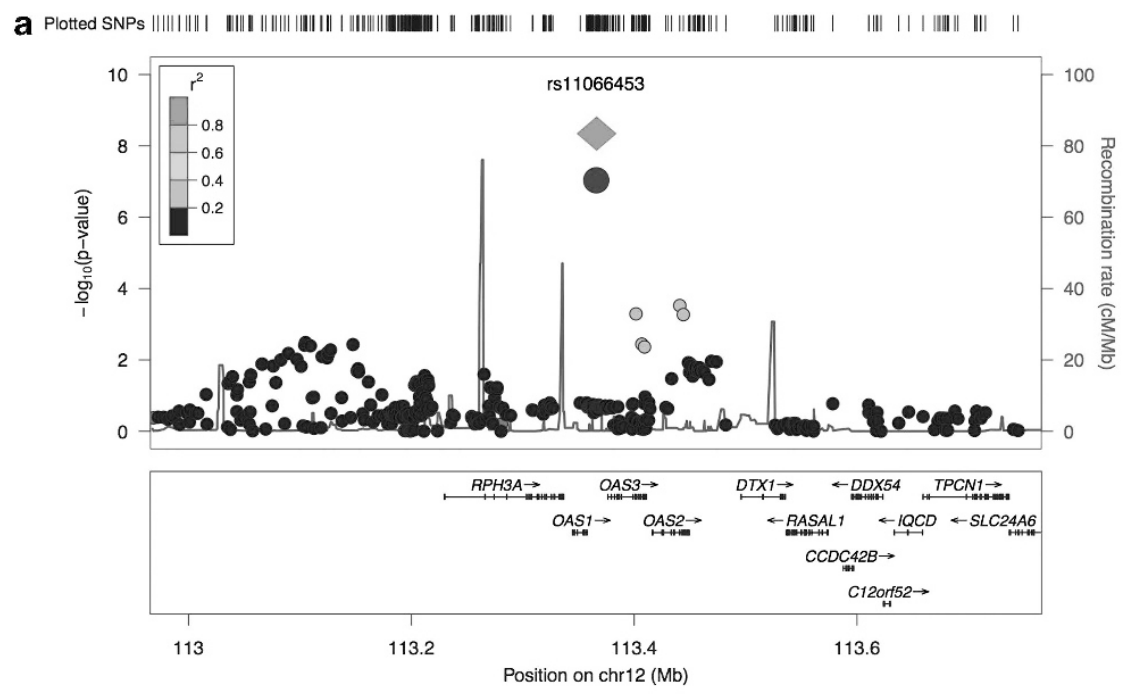

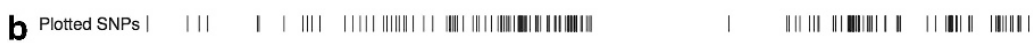

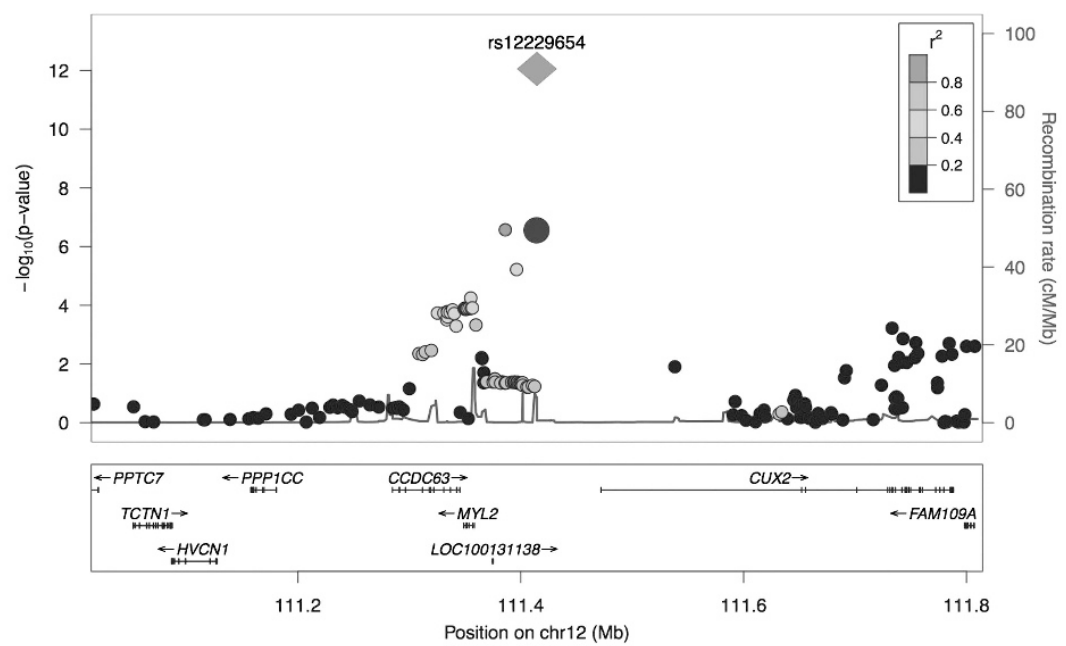

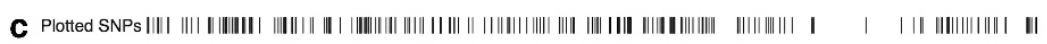

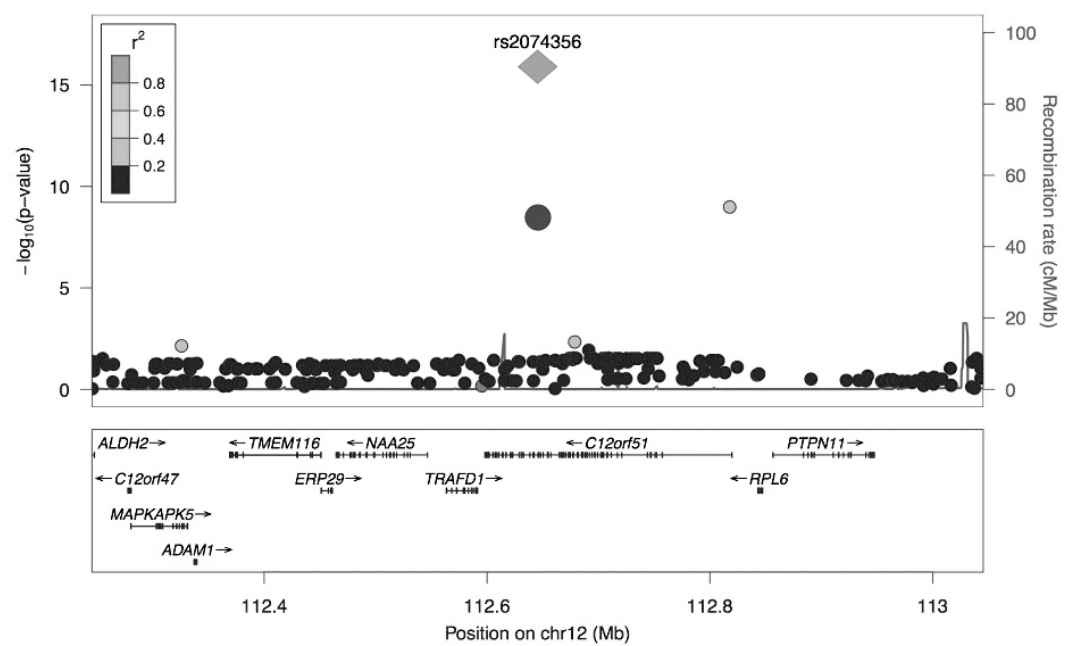

Figure 1 (a-c) Regional plots of novel variants associated with 1-h PG. The linkage disequilibrium between the lead single-nucleotide polymorphism (SNP) and the other SNPs is colored blue to red. The scatter plot and peak indicate the negative logarithm of $P$-values for each SNP. Overall, meta-analysis result is depicted by a red diamond and stage 1 result is depicted by a blue circle. A full color version of this figure is available at the Journal of Human Genetics journal online. 
In the 12q24 region, C12orf51 was found to be more strongly associated with 1-hPG (rs2074356, $\left.P=1.04 \times 10^{-16}\right)$ than fasting or 2-hPG. In addition, MYL2 (rs12229654, $P=8.83 \times 10^{-13}$ ) and OAS1 (rs1 1066453, $P=4.53 \times 10^{-9}$ ) as novel genes were further identified with 1-hPG but not significant in FPG and 2-hPG (Figure 1). For three newly identified loci, the independence for association with 1-hPG remained significant after conditional analysis.

To investigate the possible association between 1-hPG and GDM, we next investigated associations in a gestational diabetes study $(n=1710)$. Two of three loci (rs2074356, $P=2.6 \times 10^{-2}$ and rs11066453, $P=2.7 \times 10^{-2}$ ) were associated with GDM but not significant for rs12229654.

\section{DISCUSSION}

Impaired fasting glucose and impaired glucose tolerance refer to an intermediate stage for the early metabolic abnormalities that precede diabetes. The metabolic response to a carbohydrate challenge is conveniently assessed by the FPG and 2-hPG in oral glucose tolerance test (OGTT) within the standardized range by World Health Organization or American Diabetes Association.

To date, genome-wide association studies have identified novel loci with susceptibility to glycemic traits in multiple populations. However, most previous studies have a limited impact on FPG and 2-hPG values in the oral glucose tolerance testing. In an effort to identify new genetic susceptibility to early-phase post-load glucose levels, we performed a meta-analysis for glycemic traits extended with 1-hPG from 14232 non-diabetic individuals in the Korean population.

In our results, three novel variants associated with 1-hPG, located in a long-range haplotype $(1.6 \mathrm{Mb}$ at $12 \mathrm{q} 24$ region) underlying a positive selection specific to Europeans, ${ }^{12}$ were reported to have pleiotropic effects for various traits such as plasma lipid, liver enzymes and kidney function-related traits. ${ }^{13,14}$ In addition, two SNPs, rs2074356 near C12orf51 and rs11066453 near OAS1, were further associated with GDM characterized by postprandial hyperglycemia during pregnancy. Functional characterizations for C12orf51 and OAS1 have not been fully elucidated. However, C12orf51 has been proposed to participate in protein modification or ubiquitination. OAS1, encoding an enzyme of the innate immune system, has been known to play a role in mediating resistance to virus infection, regulation of cell growth and differentiation.

Our findings were convincingly supported by specific associations of susceptibility genes reported from previous studies. CDKAL1, a prominent genetic risk factor for T2D, was most significantly replicated with 1-hPG and further associated with GDM. However, GCK, which has been previously reported for genetic susceptibility to FPG, was more significantly replicated in FPG (rs1799884, $\left.P=4.53 \times 10^{-18}\right)$ than other traits $\left(P=2.82 \times 10^{-9}\right.$ for 1 -hPG and $P=2.59 \times 10^{-10}$ for 2-hPG) without any association in GDM. In addition, MTNR1B known for FPG and T2D showed similar associations with FPG and 1hPG. Considering women with GDM are at increased risk of developing T2D, these findings obviously emphasize that 1-hPG may play a role as an indicator for risk prediction or prevention in T2D. Furthermore, 1-h post-load plasma glucose levels are associated with elevated liver enzymes, ${ }^{15}$ kidney dysfunction ${ }^{16}$ coronary heart disease ${ }^{17}$ and left ventricular hypertrophy. ${ }^{18}$ Given the clinical applications, 1$\mathrm{hPG}$ as an additional predictor might be helpful for detecting individuals who are at higher risk for metabolic diseases.
In conclusion, our meta-analysis has identified three new loci associated with 1-hPG in the Korean population. Two of the identified loci were further associated with GDM. Our findings suggest the possibility of a new discovery between 1-hPG and T2D risk by large-scale genetic association studies in multiple ethnic groups. Our results provide also new insights into the genetic mechanisms underlying the glucose metabolism in the pre-diabetic or diabetogenic conditions as a diagnostic/predictive maker.

\section{CONFLICT OF INTEREST}

The authors declare no conflict of interest.

\section{ACKNOWLEDGEMENTS}

This work was supported by a grant from the Korea Center for Disease Control and Prevention (4845-301, 4851-302, 4851-307), and intramural grant from the Korea National Institute of Health (2012-N73002-00). YSC acknowledges support from the National Research Foundation of Korea (NRF) grant funded by the Korea government (MEST) (2012R1A2A1A03006155).

1 Rao, S. S., Disraeli, P. \& McGregor, T. Impaired glucose tolerance and impaired fasting glucose. Am. Fam. Physician 69, 1961-1968 (2004).

2 Ghio, A., Seghieri, G., Lencioni, C., Anichini, R., Bertolotto, A., De Bellis, A et al. 1-hour ogtt plasma glucose as a marker of progressive deterioration of insulin secretion and action in pregnant women. Int. J. Endocrinol. (2012) 460509 (2012).

3 Abdul-Ghani, M. A., Stern, M. P., Lyssenko, V., Tuomi, T., Groop, L. \& Defronzo, R. A. Minimal contribution of fasting hyperglycemia to the incidence of type 2 diabetes in subjects with normal 2-h plasma glucose. Diabetes Care 33, 557-561 (2010).

4 Scott, R. A., Lagou, V., Welch, R. P., Wheeler, E., Montasser, M. E., Luan, J. et al. Large-scale association analyses identify new loci influencing glycemic traits and provide insight into the underlying biological pathways. Nat. Genet. 44, 991-1005 (2012).

5 Dupuis, J., Langenberg, C., Prokopenko, I., Saxena, R., Soranzo, N., Jackson, A. U. et al. New genetic loci implicated in fasting glucose homeostasis and their impact on type 2 diabetes risk. Nat. Genet. 42, 105-116 (2010).

6 Saxena, R., Hivert, M. F., Langenberg, C., Tanaka, T., Pankow, J. S., Vollenweider, P. et al. Genetic variation in GIPR influences the glucose and insulin responses to an oral glucose challenge. Nat. Genet. 42, 142-148 (2010).

7 Cho, Y. S., Go, M. J., Kim, Y. J., Heo, J. Y., Oh, J. H., Ban, H. J. et al. A large-scale genome-wide association study of Asian populations uncovers genetic factors influencing eight quantitative traits. Nat. Genet. 41, 527-534 (2009).

8 Rabbee, N. \& Speed, T. P. A genotype calling algorithm for affymetrix SNP arrays. Bioinformatics 22, 7-12 (2006)

9 Gunderson, K. L., Kruglyak, S., Graige, M. S., Garcia, F., Kermani, B. G., Zhao, C. et al. Decoding randomly ordered DNA arrays. Genome. Res. 14, 870-877 (2004).

10 Devlin, B., Roeder, K. \& Wasserman, L. Genomic control, a new approach to geneticbased association studies. Theor. Popul. Biol. 60, 155-166 (2001).

11 loannidis, J. P., Patsopoulos, N. A. \& Evangelou, E. Heterogeneity in meta-analyses of genome-wide association investigations. PLoS One 2, e841 (2007).

12 Takeuchi, F., Yokota, M., Yamamoto, K., Nakashima, E., Katsuya, T., Asano, H. et al. Genome-wide association study of coronary artery disease in the Japanese. Eur. J. Hum. Genet. 20, 333-340 (2012).

$13 \mathrm{Kim}$, Y. J., Go, M. J., Hu, C., Hong, C. B., Kim, Y. K., Lee, J. Y. et al. Large-scale genome-wide association studies in East Asians identify new genetic loci influencing metabolic traits. Nat. Genet. 43, 990-995 (2011).

14 Okada, Y., Sim, X., Go, M. J., Wu, J. Y., Gu, D., Takeuchi, F. et al. Meta-analysis identifies multiple loci associated with kidney function-related traits in east Asian populations. Nat. Genet. 44, 904-909 (2012).

15 Succurro, E., Arturi, F., Grembiale, A., Iorio, F., Fiorentino, T. V., Andreozzi, F. et al. One-hour post-load plasma glucose levels are associated with elevated liver enzymes. Nutr. Metab. Cardiovasc. Dis. 21, 713-718 (2011).

16 Succurro, E., Arturi, F., Lugarà, M., Grembiale, A., Fiorentino, T. V., Caruso, V. et al. One-hour postload plasma glucose levels are associated with kidney dysfunction. Clin. J. Am. Soc. Nephrol. 5, 1922-1927 (2010).

$17 \mathrm{Wu}, \mathrm{X}$., Chen, H., Wang, Y. \& Li, H. The relationship between coronary risk factors and elevated one hour post-load plasma glucose levels in patients with established coronary heart disease. Clin. Endocrinol. (Oxf) (2013)78, 67-72.

18 Sciacqua, A., Miceli, S., Carullo, G., Greco, L., Succurro, E., Arturi, F. et al. One-hour postload plasma glucose levels and left ventricular mass in hypertensive patients. Diabetes Care 34, 1406-1411 (2011). 